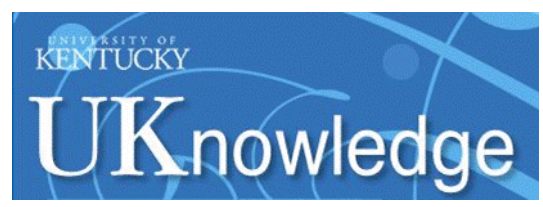

University of Kentucky

UKnowledge

\title{
Population Dynamics Based on Resource Availability \& Founding Effects: Live \& Computational Models
}

\author{
Samuel Potter \\ University of Kentucky, samuel.potter@uky.edu \\ Rebecca M. Krall \\ University of Kentucky, rebecca.krall@uky.edu \\ Susan Mayo \\ susan.mayo1961@att.net \\ Diane Johnson \\ University of Kentucky, diane.johnson@uky.edu \\ Kimberly J. Zeidler-Watters \\ Unversity of Kentucky, Kim.Zeidler@uky.edu
}

See next page for additional authors

Follow this and additional works at: https://uknowledge.uky.edu/biology_facpub

Part of the Biology Commons, and the Science and Mathematics Education Commons

Right click to open a feedback form in a new tab to let us know how this document benefits you.

\section{Repository Citation}

Potter, Samuel; Krall, Rebecca M.; Mayo, Susan; Johnson, Diane; Zeidler-Watters, Kimberly J.; and Cooper, Robin L., "Population Dynamics Based on Resource Availability \& Founding Effects: Live \& Computational Models" (2016). Biology Faculty Publications. 148.

https://uknowledge.uky.edu/biology_facpub/148

This Article is brought to you for free and open access by the Biology at UKnowledge. It has been accepted for inclusion in Biology Faculty Publications by an authorized administrator of UKnowledge. For more information, please contact UKnowledge@lsv.uky.edu. 


\title{
Population Dynamics Based on Resource Availability \& Founding Effects: Live \& Computational Models
}

\author{
Digital Object Identifier (DOI) \\ https://doi.org/10.1525/abt.2016.78.5.396
}

Notes/Citation Information

Published in The American Biology Teacher, v. 78, no. 5, p. 396-403.

(C) 2016 National Association of Biology Teachers.

Published as Potter, S., Krall, R. M., Mayo, S., Johnson, D., Zeidler-Watters, K., \& Cooper, R. L. (2016). Population dynamics based on resource availability \& founding effects: Live \& computational models. The American Biology Teacher, 78(5), 396-403. https://doi.org/10.1525/abt.2016.78.5.396. @ 2016 by National Association of Biology Teachers. Copying and permissions notice: Authorization to copy this content beyond fair use (as specified in Sections 107 and 108 of the U. S. Copyright Law) for internal or personal use, or the internal or personal use of specific clients, is granted by National Association of Biology Teachers for libraries and other users, provided that they are registered with and pay the specified fee via Rightslink ${ }^{\circledR}$ or directly with the Copyright Clearance Center.

\section{Authors}

Samuel Potter, Rebecca M. Krall, Susan Mayo, Diane Johnson, Kimberly J. Zeidler-Watters, and Robin L. Cooper 


\section{INQUIRY \&}

\section{INVESTIGATION}

\section{Population Dynamics Based on Resource Availability \& Founding Effects: Live \& Computational}

Models

SAMUEL POTTER, REBECCA M. KRALL, SUSAN MAYO, DIANE JOHNSON, KIM ZEIDLER-WATTERS, ROBIN L. COOPER

\begin{abstract}
With the looming global population crisis, it is more important now than ever that students understand what factors influence population dynamics. We present three learning modules with authentic, student-centered investigations that explore rates of population growth and the importance of resources. These interdisciplinary modules integrate biology, mathematics, and computer-literacy concepts aligned with the Next Generation Science Standards. The activities are appropriate for middle and high school science classes and for introductory college-level biology courses. The modules incorporate experimentation, data collection and analysis, drawing conclusions, and application of studied principles to explore factors affecting population dynamics in fruit flies. The variables explored include initial population structure, food availability, and space of the enclosed population. In addition, we present a computational simulation in which students can alter the same variables explored in the live experimental modules to test predictions on the consequences of altering the variables. Free web-based graphing (Joinpoint) and simulation software (NetLogo) allows students to work at home or at school.
\end{abstract}

Key Words: Live models; NetLogo; Joinpoint; NGSS; Drosophila; population dynamics.

\section{$\bigcirc$ Introduction}

The Next Generation Science Standards (NGSS; NGSS Lead States, 2013) focus on exploration of natural phenomena through practices consistent with those that scientists employ in the development of scientific knowledge. One of the practices that separate NGSS from previous national science standards and frameworks is the use of models as tools for thinking, visualizing, and making sense of phenomena and experience (Krajcik \& Merritt, 2012). Students can use models to make sense of what they observe and to make their thinking visible. Doing so allows them to share their explanations with other students and refine their models as they continue to study a phenomenon in different contexts. NGSS recommends that models be used in developing, evaluating, using, and revising explanations and predictions of science phenomena. Here, we present three modules that use fruit flies (Drosophila melanogaster) to explore the effects of initial population size, food availability, and enclosure space on population dynamics. The activities use modeling to support students' development of explanations to account for observed phenomena in population growth (Oh \& Oh, 2011). The modules also apply common science practices that biomedical researchers employ today as they tackle population issues, using the fruit fly as model (Pulver et al., 2011).

\section{$\bigcirc$ Life Cycle of the Fruit Fly \& the Population Modules}

Fruit flies are used as a model organism in research laboratories and classrooms around the world. They are easily obtainable from suppliers, and many people have them in their own homes. They can be purchased cheaply, or they can be captured for free by placing a banana in an open jar for a day or two. Fruit flies are easily cared for, and there are no health or ethical concerns regarding their use in classrooms.

The life cycle of $D$. melanogaster is simple and predictable. Females lay up to 500 eggs on fermenting fruit. The male fertilizes the eggs, and the larvae emerge in 24-30 hours. The short, segmented, whitish-yellow larvae crawl around, gorging themselves on available food sources. They progress through three distinct phases within the larval stage, as denoted by changes in their mouth hooks (small, black hooks at their anterior; it is not relevant to discern the different

larval phases in the modules presented here). Toward the end of the larval stage, they begin climbing the walls of their enclosure, eventually becoming immobile as they transition into the pupal stage. At this time they turn dark brown and form a hard outer shell. They will remain in this state for about a week, after which time they

The American Biology Teacher, Vol. 78, No 5, pages. 396-403, ISSN 0002-7685, electronic ISSN 1938-4211. ( 2016 National Association of Biology Teachers. All rights

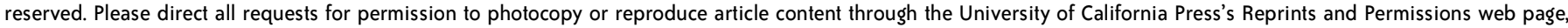
www.ucpress.edu/journals.php?p=reprints. DOI: 10.1525/abt.2016.78.5.396. 
emerge as adult fruit flies. An adult female fruit fly can begin to mate about two days after emerging.

Educational modules can be designed to explore a variety of biological processes using the life cycle of $D$. melanogaster as a model. Here, we use fruit flies to examine population dynamics. The first module explores population growth by comparing a population that begins with one female fruit fly and a population that begins with three females. Investigations focus on the total numbers of individuals within a population and the rates of growth across the different treatments. The second module examines the effect of food availability on population growth, and the third explores the effect of enclosure size on growth of the population. More specifically, this last module examines how the dynamics of similar populations differ if one population has significantly more space available than the other. Separately, each module highlights one limiting factor in population dynamics. Together, the modules illuminate relationships among different abiotic factors that influence population dynamics, with a specific focus on population growth. The three modules combined cover the three-dimensionality of NGSS (i.e., Scientific and Engineering Practices, Crosscutting Concepts, and Disciplinary Core Ideas) using authentic science investigations. Further, the modeling activities promote critical analysis and use of empirical data to construct working explanations in ways consistent with practices that Krajcik and Merritt (2012) recommended to promote student learning in science. NGSS connections for each module are presented in two tables at the end of this article.

\section{Overview of Modules}

The modules are presented as three distinct investigations that can be implemented separately or concurrently as a modular set. Each module requires setup of the fruit fly environments and anesthetization chambers (described in the following sections). Setup procedures are simple and can be performed by students from middle grades up. Data from investigations will offer sufficient evidence for students to formulate working explanations on the effect of each variable (i.e., initial population, food availability, space availability) on population growth. Thus, the modules work well early in a unit on population dynamics, interactions within ecosystems, and similar topics. Table 1 summarizes variables explored in the modules and expected outcomes.

\section{O Preparation Procedures for Three Population Dynamics Modules}

The following section summarizes procedures for setting up the environments and anesthetizing fruit flies. Table 2 summarizes materials needed for the three modules. A web link to the full modules - including instructions, video clips of procedures, data tables, and additional material - is given at the end of the article.

\section{Impact of Initial Population (Module 1)}

The first module examines how properties of the initial population alter a population's dynamics. Six vials of equal size need to be prepared for this investigation, each containing equal amounts of a food substance; we recommend using $25 \times 95 \mathrm{~mm}$ vials and moist yellow corn meal. After the food has set, each vial should be labeled with a letter (A-F) for identification throughout the investigation. It is recommended that students prepare their own vials with careful guidance from the teacher. After each vial has been sealed with a cotton ball, the apparatus is prepared for fly occupancy.

Fruit flies will need to be anesthetized and selected for each vial. Wild-type fruit flies can be anesthetized using any variety of methods, but placing the vial in crushed ice offers a quick and easy anesthetization for this procedure (more details are given on our web page; see "Web Link" below).

Once the fruit flies have been anesthetized, students can use a hand lens, dissecting scope, or even the naked eye to identify the sex of each fly using secondary sexual characteristics, such as appearance of the genitals and sex combs. The sex combs (black bristle areas on the male's forelegs) are an efficient way to differentiate males and females and can be viewed with the naked eye. With the use of a small paintbrush, the flies can be brushed off a sheet of paper and into a container.

In each of the first three vials (A-C), place one anesthetized male and one female. Keep the vial on its side to prevent the flies from falling into the food. Insert the cotton ball into the vial, and wait for the flies to regain consciousness before turning the vial upright. Repeat the procedure with vials D-F but place three females (rather than one) in each of these vials. Once the flies have all regained consciousness in all six vials, turn them upright and place the vials in a safe location that receives regular day and night light cycles. If each group of students has its own sets of vials, make sure they are differentiated from each other by labels or marks.

Monitor the vials daily for pupa formation, as indicated by larvae climbing the vial walls, becoming stationary, and turning dark brown. After the first pupa forms, the vials should be checked for new pupae twice daily. Each pupa should be marked with a finepoint permanent marker on the exterior of the vial. In a data table, document the date, time, and number of new pupae after each monitoring period. Continue documenting new pupa formation until a new adult emerges (ecloses) from its pupal casing.

At this point, remove all adults from all vials in order to differentiate the original population from the $\mathrm{F}_{1}$ population. For classes that

Table 1. Summary of variables and expected outcomes for three population dynamics modules.

\begin{tabular}{|l|l|l|l|}
\hline Criteria & Module 1 & Module 2 & Module 3 \\
\hline Variable explored & $\begin{array}{l}\text { Number of females in initial } \\
\text { population (1 vs. 3) }\end{array}$ & Food availability & Space availability \\
\hline Expected finding & $\begin{array}{l}\text { Populations beginning with } \\
\text { more females grow larger and } \\
\text { faster than initial populations } \\
\text { with only one female. }\end{array}$ & $\begin{array}{l}\text { Populations with greater food } \\
\text { availability grow larger than } \\
\text { populations with less available } \\
\text { food. }\end{array}$ & $\begin{array}{l}\text { Populations with greater space } \\
\text { availability grow faster than } \\
\text { populations with less available } \\
\text { space. }\end{array}$ \\
\hline
\end{tabular}


Table 2. Summary of materials needed for three population dynamics modules.

\begin{tabular}{|c|c|}
\hline Module 1 & $\begin{array}{l}\text { For each student group: } \\
\text { - } 6 \text { small vials ( } 25 \times 95 \mathrm{~mm} \text {; e.g., catalog no. 32-120, https://geneseesci.com/) } \\
\text { - } 1 \text { fine-point permanent marker } \\
\text { - } 6 \text { cotton balls } \\
\text { - Fly food substance (e.g., yellow corn meal) } \\
\text { - Wild-type D. melanogaster (6 males, } 12 \text { females) } \\
\text { - Means to anesthetize flies (carbon dioxide, ether, FlyNap, cold) } \\
\text { - Hand lenses or a dissecting scope } \\
\text { - Paintbrush or forceps (to move flies) } \\
\text { - Guide to determing fruit fly sex } \\
\text { - Data table } \\
\text { - Computer with Joinpoint, Excel, or other spreadsheet software }\end{array}$ \\
\hline Module 2 & $\begin{array}{l}\text { For each student group: } \\
\text { - } 3 \text { large, clear, plastic food-storage containers (size of a shoe box) } \\
\text { - } 1 \text { fine-point permanent marker } \\
\text { - } 3 \text { cotton balls } \\
\text { - Play-Doh } \\
\text { - } 3 \text { baby food jars (or similar) } \\
\text { - } 3 \text { small Petri dishes } \\
\text { - } 3 \text { large Petri dishes } \\
\text { - } 3 \text { sheets of filter paper } \\
\text { - Digital balance } \\
\text { - Fly food substance (e.g., yellow corn meal) } \\
\text { - Wild-type D. melanogaster ( } 3 \text { males, } 3 \text { females) } \\
\text { - Means to anesthetize flies (carbon dioxide, ether, FlyNap, cold) } \\
\text { - Hand lenses or } 1 \text { dissecting scope } \\
\text { - Paintbrush or forceps (to move flies) } \\
\text { - Guide to determining fruit fly sex } \\
\text { - Data table } \\
\text { - Computer with Excel or other spreadsheet software }\end{array}$ \\
\hline Module 3 & $\begin{array}{l}\text { For each student group: } \\
\text { - } 3 \text { large vials (6 oz., square bottom; e.g., catalog no. 32-130BF, https://geneseesci.com/) } \\
\text { - } 1 \text { fine-point permanent marker } \\
\text { - } 3 \text { large cotton balls or sponge stoppers } \\
\text { - Fly food substance (e.g., yellow corn meal) } \\
\text { - Wild-type D. melanogaster ( } 3 \text { males, } 9 \text { females) } \\
\text { - Means to anesthetize flies (carbon dioxide, ether, FlyNap, cold) } \\
\text { - Hand lenses or } 1 \text { dissecting scope } \\
\text { - Paintbrush or forceps (to move flies) } \\
\text { - Guide to determining fruit fly sex } \\
\text { - Data table } \\
\text { - Data from Module } 1 \\
\text { - Computer with Joinpoint or other spreadsheet software }\end{array}$ \\
\hline
\end{tabular}

do not meet every day, at least the adults can be removed on a set schedule. In a new data table, begin counting the newly eclosed adults twice daily. Just as before, document date, time, and number of new adults. After checking each vial, remove the newly eclosed adults. Continue this process until no new adults form or until sufficient data have been collected to draw conclusions on population sizes across the two environments. This module also provides students a quick, qualitative view of the results; they can readily note differences in the number of pupae in the two environments, thus justifying the need to count pupae over time (Coffey \& Atkinson, 1996).

\section{Impact of Food Availability (Module 2)}

The second module examines how food availability can alter a population's dynamics. A large, rectangular, clear plastic storage container (shoe box size) with holes cut in the lid serves as the environment for the three trials. Setup of the environment includes creating a location for the food source and a water supply, as well as creating a fly-proof seal where the lid and base of the container meet to prevent fruit flies from escaping into the classroom. Modeling clay can be used to create this seal (or a Tupperware-type container with a snap-shut lid could be used for a better seal, with 
holes cut in the lid). Begin setup by cutting a small hole $(\sim 1 \mathrm{~cm}$ in diameter; small enough that a piece of cotton can plug the hole) in the lower side of the storage container, about a fourth of the way down along the long side. Then snap the lid onto the container, and invert the container such that the lid is on the table and the bottom with the hole is on top. On the lid, use a marker to mark the spot directly below the hole when the container is closed. The hole will serve as the entry point when adding flies to the environment and adding water over the food dish to keep the food moist. Remove the lid, and place it on a flat surface. If the lid is not sealing well, press the modeling clay (we found that Play-Doh works well) into the ridge of the lid that makes contact with the container

Next, prepare a water apparatus using the jar, a large Petri dish, and filter paper. Fill the jar with water, and line the Petri dish with filter paper. Place the Petri dish over the mouth of the jar, and invert the apparatus such that the jar is sitting upside-down in the Petri dish and water can saturate the filter paper. Place this apparatus on the interior of the lid of the container, opposite the side of the lid previously marked. Weigh out 0.5 grams of fly food (we recommend yellow corn meal) and place it in a small Petri dish on the marked spot of the lid. The small Petri dish should be under the hole cut in the container. This way water drops can be added throughout the experiment to keep the food moist.

With the food dish and water supply in place, snap the container on the lid such that the container creates the four walls and roof of the enclosure. The modeling clay will extrude toward the interior and exterior of the container. Using more modeling clay, pack it in the lip of the lid all the way around the container. The goal is to create a fly-proof seal. Prepare a cotton ball to be placed in the hole above the food dish. Complete the preparation of the other two containers in a similar manner using $1.0 \mathrm{~g}$ and $1.5 \mathrm{~g}$ of food in the second and third containers, respectively. Mark each container A-C for identification purposes.

With the enclosures prepared, the flies can be added (following the same fly-selection procedure described for Module 1). Place two anesthetized fruit flies, one male and one female, into the first container (marked A) through the small hole above the water apparatus. Be careful not to allow anesthetized flies to fall into the food. Seal the hole with the cotton ball. Complete this process two more times for the remaining containers. Place the three containers in a safe place with normal light and dark cycles.

Monitor the containers periodically. The food will need to be moistened every three to four days. Using the hole that's plugged with a cotton ball, carefully add water to the food with a syringe, pipette, or squirt bottle. Be diligent not to allow any of the flies to escape. When all flies within a container die, open the container and document the number of dead adults. It may take as long as two months for the populations to die out.

\section{Impact of Space Availability (Module 3)}

The last module examines how increasing the available space alters a population's dynamics. To complete this module, students will need the data from Module 1 for comparison. Large vials (6 oz.) will serve as the environments in this module. Prepare the vials for fruit fly occupancy in a similar manner as described for Module 1. Since the vials are larger, cotton balls may be too small to seal the mouth of the vial. A sponge stopper may be required. Sponge stoppers can be purchased commercially or made from highdensity polyurethane foam purchased at a local box store or fabric store. This allows air to move freely in and out of the vials while keeping the flies sealed inside. As described for Module 1, anesthetize the flies to be placed in the vials. In each of the three vials, place one male and three females to allow the population to grow quickly for observed effects.

As described above, monitor the vials daily for pupa formation. After the first pupa forms, the vials should be checked for new pupae twice daily. In this module the newly emerged flies should be left in the containers to examine the total number of adults that the limited food can sustain (thus, sustainability of a population is measured). Each pupa should be marked with permanent marker on the exterior of the vial. In a data table, document the date, time, and number of new pupae for each monitoring period. Continue documenting new pupa formation until the total elapsed time is roughly equivalent to the elapsed time in the pupation portion in Module 1.

\section{O Analyzing Collected Data}

Analysis of data collected from Modules 1 and 3 can be performed in similar ways. In each investigation, students should have created tables to include dates, times, and numbers of pupae and adults for each observation. A graph can be created to illustrate the patterns for both modules on the same graph. Alternatively, students can be given Excel templates to guide their data input. Prepared datasheets are available on the accompanying web page (see "Web Link" below). Excel will adjust the data into the format necessary for use in Joinpoint, a freeware statistical analysis program. Students can use Joinpoint to perform piecewise linear regressions on the data, graph the data as a scatterplot, and output the regressions on the graph and in tables. These exercises allow students to compare how quickly the populations grew during different phases of the experiment. The benefit of using piecewise linear regressions is that students are more likely to be familiar with the basic concept of the slope of a line than with quadratic or exponential functions and their applications. Collaboration with a mathematics teacher also can offer an opportunity for students to explore and critique different methods for analyzing the data.

The data from Module 2 will be analyzed using Excel. After using the provided template to input data, students will be able to create a bar graph that displays how food availability influences population size. Unlike the analysis performed in Modules 1 and 3, this process relies less on interpreting statistical outputs. Graphing principles applied in this module include how to read a graph, identify patterns from the graph, and draw conclusions from the data.

\section{Drawing Conclusions \& Student Assessment}

After collecting and analyzing their data, students will be ready to draw conclusions based on their analysis. The text that accompanies each module (see "Web Link" below) includes questions to guide students through the conclusion process. Joinpoint graphs 
and regressions from Module 1 will illustrate that initial populations with more females can both grow faster and larger. This can be determined by examining the slopes of the regressions and comparing the graph for the trials with two adults to the graph for the trial with four adults. The same process is applied to the data from Module 3 (the exception, of course, being that the data analysis from Module 3 is compared to the comparable analysis performed in Module 1). The comparison should show that more space allows populations to grow faster and larger. Students should be required to use data they collect to substantiate claims they make in conclusions.

Conclusions from Module 2 are not as statistically obvious as those from Modules 1 and 3. Students will create bar graphs from their data and then make height comparisons across the bars to draw conclusions, rather than relying on statistical outcomes from a linear regression. By comparing the heights of the bars within the graph, students should observe a relationship in which more food corresponds to larger populations.

In addition to the questions used to guide students in drawing conclusions, each module includes two sets of questions at the end of the module. Conclusion questions guide students to describe their conclusions and reflect on how the results may have altered or built upon prior knowledge. Challenge questions allow students to bring components of the module together to synthesize new ideas and make predictions. They also require students to apply the principles discovered in the module to other scenarios.

\section{Modifications \& Extensions}

Since each module addresses an individual component that influences population dynamics, teachers may elect to utilize some modules and not others. This allows modifications to meet unit outcomes with respect to both time restrictions and the level of rigor intended for learning outcomes. Module 2, for example, requires less in-depth analysis than is required in Modules 1 and 3, employing the use of bar graphs to draw conclusions.

Teachers can also modify the modules to use low-tech options for data analysis. The Joinpoint analysis, for example, could be replaced by analysis by hand. Although it would be less statistically accurate, students could plot the data points on graph paper and draw their own piecewise lines of fit. They could then use basic algebra skills to compute the slopes of those lines. This method should still elucidate the principles at work, and it would also give students valuable practice at graphing data by hand. If a classroom is using Vernier hardware (http://www.vernier.com), students also can generate graphs using data they collected and use Vernier's built-in graphical functions for calculating the slope of lines.

Modifications can easily be implemented in these modules to expand the study focus. In addition to initial population structure, food availability, and space availability, students could design experiments to address how other variables influence population dynamics. Light, temperature, and moisture variance, for example, could be tested to observe the effect each of these factors has on how quickly or to what size a population grows. Although these variables may not have any effect, students would thus get more exposure to experimental design and population dynamics applicable in various fields (Wall et al., 2014).

\section{O Population Modeling}

Several types of models are presented in these exercises. The use of live flies in various types of environments to monitor population dynamics directly can serve as a model to represent other organisms, such as humans. The food-limitation environment in Module 2 models the effects of access to food on population growth. Students can use data from Module 1 and Module 3 to make predictions for Module 2 outcomes. In addition, they can create explanatory models to illustrate their explanations for observed outcomes. Throughout the investigations, models should be revisited and modified as more data are acquired and processes are discussed. Additional readings can substantiate students' claims and further their understanding. Thus, the four main aspects of using models (developing, evaluating, using, and revising) naturally fall into place with these populationdynamics investigations (Krajcik \& Merritt, 2012).

In conjunction with these modules, we have developed computer simulations that demonstrate the same principles. Using Netlogo modeling software, students can run a simulation that corresponds to each module. Just as in the live models, students will be able to alter specific variables, such as amount of food and number of initial females, to test their hypotheses. In the space of one classroom session, they can run several experiments to explore effects of several variables because of the short time necessary to run each trial. Computer simulations are both cheaper and faster to implement than their live counterparts because the software is free and the time to run computer simulations is significantly less than for the live experiments. In one class session, students can easily address other situations, such as the number of males in the initial population (i.e., three males compared to one male). All three modules for the computational focus could, in fact, be completed within a single class period. In most cases, it's best to use simulations after the students have experienced the physical phenomena (Sneider et al., 2014), because computer simulations remove the personal interaction of running live experiments and can leave students unclear about the authenticity of simulation outcomes.

\section{O Classroom Implementation of Modules}

All three modules have been implemented in middle and high school classrooms. Over 200 middle school students from 10 seventh-grade classes participated in the module investigations. In addition, 100 high school students enrolled in AP biology classes participated. In general, students were highly engaged in using the models.

Outcomes from the implementation revealed that Module 2 was well adapted for the middle school classroom whereas Modules 1 and 3 were more appropriate for high school classes. Students at both levels were highly engaged in the investigations, but high school students quickly identified a variety of population factors to test, such as potential environmental conditions affecting population dynamics (constant dark or light; cold temperature or presence of a heat lamp; substances added to the food), whereas middle school students required more scaffolding to identify possible factors. Students at all levels worked in twos or threes on the investigations. High school students also had prior knowledge of Excel and graphical analysis software on computers. The middle school 
students were less experienced with these programs and had limited access to technology. Therefore, high school students were able to complete the NetLogo environmental simulations whereas middle level students were limited to the live investigations and graphing using paper-and-pencil methods. Middle school students also had difficulty creating graphs and identifying corresponding axis scales, which underscores the need for students to participate in investigations requiring these skills. Completing all three modules simultaneously proved to streamline the implementation and offered students a complex dataset to compare findings across the experimental environments.

Several issues that emerged in module implementation included sorting female and male flies and weighing the food substance. Sorting of fruit flies was best completed by providing students vials of 10-15 flies. Larger numbers of flies in vials made the task more difficult for students and created more concern that the flies would wake up from cold anesthesia before sorting was complete. A classroom helper was used to distribute the sexes into the respective experimental containers

Another bottleneck was weighing of fly food. Wet cornmeal was used in the investigations. One electronic scale per class proved to be too limiting in weighing food material for all of the groups. Three or four scales sped up the weighing process, making it more manageable. The weighing out of the food could be done ahead of time, but that would eliminate an opportunity for middle school students to learn how to use an electronic balance. For example, during the implementations, many of the middle school students were not familiar with tarring the weigh paper before measuring out the food. This was a new skill learned as they set up their experimental environments.

Other small issues that might need to be addressed include escaped flies in the classroom and planning a schedule to moisten the fly food. Fruit flies that escape during experimental setup can easily be caught using a variety of fly traps. A simple trap can be created with a plastic cup and paper towel or coffee filter. First, place a small amount of food in the base of a plastic cup. Then create a funnel from a coffee filter or paper towel, cutting a small hole at the very base of the funnel. Place the funnel in the cup, folding the open ends over the cup edge and securing the ends with tape or a rubber band. The flies will crawl into the cup to find the food but will not be able to find a way out. Food moistening also needs to be scheduled weekly. Moistening the food on Friday ensures that the flies will have a food source during the weekend. One additional day, Tuesday or Wednesday, also might be added to the schedule to keep the food moist.

Assessment data from module implementation will be presented in subsequent publications. Pre-assessments indicated that students had little understanding of the effect initial female populations might have on population growth, whereas students demonstrated greater understanding of the effect of limited food availability on population growth. However, their understanding of the role that space plays in population dynamics was also limited. Many middle school students held the naive notion that fruit flies are too small for space size to make a difference in their population size. Analysis of pre- and post-assessments will be presented in future publications.

\section{Conclusion}

With the world on the cusp of a population crisis, there has never been a more important time for students to understand what factors influence a population's growth (UNESCO, 1999; United Nations, 2012, 2013; Lutz, 2013). These modules incorporate biological concepts, mathematical analysis, and computer skills to expound on some of the intricacies of how a population changes. The experiments

Table 3. Summary of NGSS middle school connections to three fly population modules.

\begin{tabular}{|c|c|c|c|c|}
\hline $\begin{array}{l}\text { Performance } \\
\text { Expectation }\end{array}$ & $\begin{array}{l}\text { Science \& Engineering } \\
\text { Practices }\end{array}$ & Disciplinary Core Ideas & $\begin{array}{l}\text { Crosscutting } \\
\text { Concepts }\end{array}$ & Mathematics \\
\hline MS-LS1-5 & $\begin{array}{l}\text { - Deloping and Using Models } \\
\text { - Constructing Explanations } \\
\text { and Designing Solutions } \\
\text { - Engaging in Argument } \\
\text { from Evidence } \\
\text { - Obtaining, Evaluating, and } \\
\text { Communicating } \\
\text { Information } \\
\text { - Scientific Knowledge Is Based } \\
\text { on Empirical Evidence }\end{array}$ & $\begin{array}{l}\text { LS1.B: Growth and } \\
\text { Development of Organisms }\end{array}$ & $\begin{array}{l}\text { - Cause and Effect } \\
\text { - Scientific } \\
\text { Knowledge } \\
\text { Assumes an Order } \\
\text { and Consistency } \\
\text { in Natural Systems }\end{array}$ & \multirow[t]{2}{*}{$\begin{array}{l}\text { MS-LS3-2: Model with } \\
\text { mathematics } \\
\text { (6.SP.B.4, 6.SP.B.5) }\end{array}$} \\
\hline MS-LS2-1 & & $\begin{array}{l}\text { LS2.A: Interdependent } \\
\text { Relationships in Ecosystems } \\
\text { LS2.C: Ecosystem Dynamics, } \\
\text { Functioning, and Resilience }\end{array}$ & $\begin{array}{l}\text { - Cause and Effect } \\
\text { - Stability and } \\
\text { Change } \\
\text { - Scientific } \\
\text { Knowledge } \\
\text { Assumes an Order } \\
\text { and Consistency in } \\
\text { Natural Systems }\end{array}$ & \\
\hline
\end{tabular}


Table 4. Summary of NGSS high school connections to three fly population modules

\begin{tabular}{|c|c|c|c|c|}
\hline $\begin{array}{l}\text { Performance } \\
\text { Expectation }\end{array}$ & $\begin{array}{l}\text { Science \& Engineering } \\
\text { Practices }\end{array}$ & Disciplinary Core Ideas & Crosscutting Concepts & Mathematics \\
\hline HS-LS2-1 & \multirow{3}{*}{$\begin{array}{l}\text { - Developing and Using } \\
\text { Models } \\
\text { - Constructing } \\
\text { Explanations and } \\
\text { Designing Solutions } \\
\text { - Engaging in Argument } \\
\text { from Evidence } \\
\text { - Obtaining, Evaluating, } \\
\text { and Communicating } \\
\text { Information } \\
\text { - Scientific Knowledge Is } \\
\text { Based on Empirical } \\
\text { Evidence }\end{array}$} & $\begin{array}{l}\text { LS2.A: Interdependent } \\
\text { Relationships in } \\
\text { Ecosystems }\end{array}$ & $\begin{array}{l}\text { - Cause and Effect } \\
\text { - Scale, Proportion, and } \\
\text { Quantity }\end{array}$ & MP.2: Reason Abstractly \\
\hline HS-LS2-2 & & $\begin{array}{l}\text { LS2.A: Interdependent } \\
\text { Relationships in } \\
\text { Ecosystems }\end{array}$ & \multirow{2}{*}{$\begin{array}{l}\text { - Cause and Effect } \\
\text { - Stability and Change } \\
\text { - Scientific Knowledge } \\
\text { Assumes an Order and } \\
\text { Consistency in Natural } \\
\text { Systems }\end{array}$} & \multirow{2}{*}{$\begin{array}{l}\text { MP.4: Model with } \\
\text { Mathematics } \\
\text { HSN.Q.A.3: Choose level } \\
\text { of accuracy }\end{array}$} \\
\hline HS-LS2-6 & & $\begin{array}{l}\text { LS2.C: Ecosystem } \\
\text { Dynamics, Functioning, } \\
\text { and Resilience } \\
\text { LS4.C: Adaptation } \\
\text { LS4.D: Biodiversity and } \\
\text { Humans }\end{array}$ & & \\
\hline
\end{tabular}

performed are simple and consist mostly of creating an environment in which the populations can thrive. The modules also take up a limited amount of class time; the data collection takes but a few minutes a day. The principles learned via these experiments will grant students a better understanding of both the ecological underpinnings of a population and the implications for current human population growth. The investigations presented in all three modules offer the potential to study a diverse array of factors that affect population dynamics, such as temperature, type of food, pollutants in the food, noise, and lighting. For more advanced classes, studies can include exploration of the effect that mutations have on Drosophila populations. Science supply warehouses, such as Bloomington Stock Center (http://flystocks.bio. indiana.edu/), offer established mutations that correlate to human diseases (Taniguchi \& Moore, 2014; Casci \& Pandey, 2015; Sun \& Chen, 2015; Vos et al., 2015), offering the potential for students to pursue wide-ranging inquiries and research on human-related diseases. This provides a stimulating approach for students to learn science and is one reason the national standards implemented this model over a decade ago (National Research Council, 2000). Facilitating guided investigations and open inquiry while acquiring new knowledge creates a challenge for many teachers (Appleton, 1995; Abrams et al., 2007; Nadelson, 2009), but these modules are designed to assist teachers with both. Tables 3 and 4 summarize the main connections to NGSS for middle and high school grades. Only the main connections are listed. The interdisciplinary nature of the investigations provides opportunities for a diversity of connections across NGSS and Common Core State Standards for mathematics.

A web page developed to support implementation of the three modules can be found at the link that follows. The web page includes datasheet templates, module procedures, and student questions, and explanatory videos are available to support teachers in implementing the modules.

\section{Web Link}

http://web.as.uky.edu/Biology/faculty/cooper/Population\%20dynamics\% 20examples\%20with\%20fruit\%20flies/TheAmericanBiologyTeacherPopulationDynamicsWebpage.html

\section{References}

Abrams, E., Southerland, S.A. \& Silva, P. (Eds.) (2007). Inquiry in the Classrooms: Challenges and Opportunities. Greenwich, $\mathrm{CT}$ : Information Age.

Appleton, K. (1995). Student teachers' confidence to teach science: is more science knowledge necessary to improve self-confidence? International Journal of Science Education, 17, 357-369.

Casci, I. \& Pandey, U.B. (2015). A fruitful endeavor: modeling ALS in the fruit fly. Brain Research, 1607, 47-74.

Coffey, A. \& Atkinson, P. (1996). Making Sense of Qualitative Data: Complementary Research Strategies. Thousand Oaks, CA: SAGE.

Krajcik, J. \& Merritt, J. (2012). Engaging students in scientific practices: what does constructing and revising models look like in the science classroom? Science and Children, 49(7),10-13.

Lutz, W. (2013). The Future Population of the World: What Can We Assume Today? London, UK: Dunstan House.

Nadelson, L.S. (2009). How can true inquiry happen in K-16 science education? Science Educator, 18(1), 48-57.

National Research Council (2000). Inquiry in the National Science Education Standards: A Guide for Teaching and Learning. Washinģton, DC: National Academy Press.

NGSS Lead States (2013). Next Generation Science Standards: For States, By States. Washington, DC: National Academies Press.

Oh, P.S. \& Oh, S.J. (2011). What teachers of science need to know about models: an overview. International Journal of Science Education, 33, $1109-1130$.

Pheeney, P. (1997). Hands-on, minds-on: activities to engage our students. Science Scope, 21(4), 30-33.

Pulver, S.R., Cognigni, P., Denholm, B., Fabre, C., Gu, W.X.W., Linneweber, G. et al. (2011). Why flies? Inexpensive public engagement exercises to explain the value of basic biomedical research on Drosophila melanogaster. Advances in Physiology Education, 35, 384-392.

Sneider, C., Stephenson, C., Schafer, B. \& Flick, L. (2014). Computational thinking in high school science classrooms. Science Teacher, 81(5), 53-59.

Sun, M. \& Chen, L. (2015). Studying tauopathies in Drosophila: a fruitful model. Experimental Neurology, 274, 52-57.

Taniguchi, H. \& Moore, A.W. (2014). Chromatin regulators in neurodevelopment and disease: Analysis of fly neural circuits provides insights: networks of chromatin regulators and transcription factors underlie Drosophila neurogenesis and cognitive defects in 
intellectual disability and neuropsychiatric disorder models. Bioessays, 36, 872-883.

UNESCO (1999). United Nations educational, scientific and cultural organization education and population dynamics: mobilizing minds for a sustainable future. Available online at http://unesdoc.unesco.org/ images/0011/001163/116355eo.pdf.

United Nations (2012). UN System Task Team on the post-2015 UN development agenda: population dynamics thematic think piece. Available online at http://www.un.org//millenniumgoals/pdf/Think\% 20Pieces/15_population_dynamics.pdf.

United Nations (2013). Population dynamics in the context of the post-2015 development agenda beyond 2015. Available online at http://www. beyond2015.org/sites/default/files/Population\%20Dynamics.pdf.

Vos, M., Verstreken, P. \& Klein, C. (2015). Stimulation of electron transport as potential novel therapy in Parkinson's disease with mitochondrial dysfunction. Biochemical Society Transactions, 43, 275-279.
Wall, J., Wittemyer, G., Klinkenberg, B. \& Douģlas-Hamilton, I. (2014). Novel opportunities for wildlife conservation and research with real-time monitoring. Ecoloģical Applications, 24, 593-601.

SAMUEL POTTER (samuel.potter@uky.edu) is an undergraduate Agricultural Biotechnology major and ROBIN L. COOPER (rlcoopl@uky.edu) is an Associate Professor in the Department of Biology, University of Kentucky, 101 T.H. Morgan Bldg., Lexington, KY 40506. REBECCA M. KRALL (rebecca.krall@uky.edu) is an Associate Professor in the Department of STEM Education, SUSAN MAYO (susan.mayo1961@att.net) is a PIMSER Reģional Teacher Partner, DIANE JOHNSON (diane.johnson@uky.edu) is an Assistant Director of PIMSER, College of Education, and KIM ZEIDLERWATTERS (kim.zeidler@uky.edu) is the Director of PIMSER, College of Education, University of Kentucky, 1737 Russell Cave Rd., Lexinģton, KY 40505.

\section{Cogent}

Why read a case study when you can experience one?

Can you save Clark? In our Osmosis Interactive Case, your students will act as a veterinarian to try and save the life of a calf having seizures. Students fly into his brain to see, explore and interact with cells, ions and molecules.

Our engaging real world scenarios, allow students to collect \& analyze data, form \& test hypotheses, and communicate findings to teachers in real-time. Proven to help students learn difficult biology concepts and improve their critical thinking skills.

Your students will never view science the same way again!

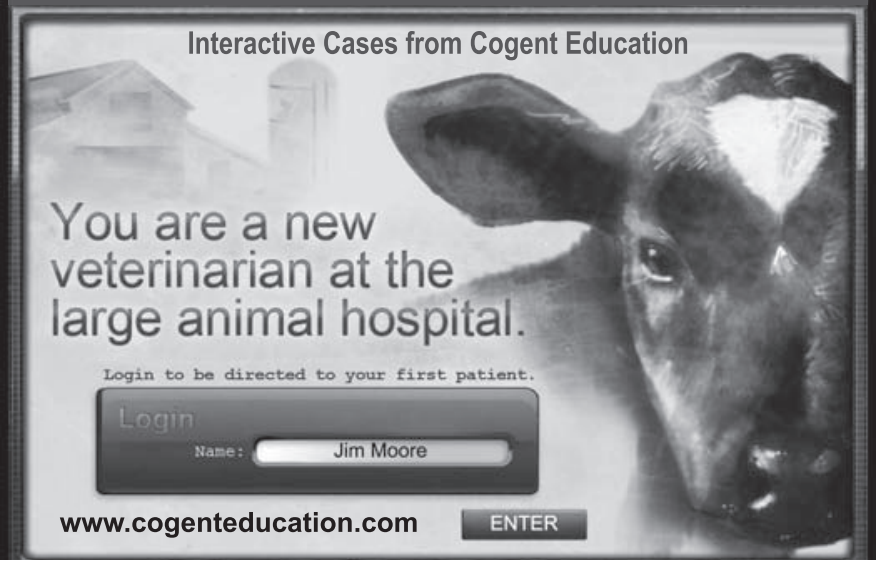

